\title{
Analysis on Improvement of Comprehensive Competency in Undergraduates by Music Education
}

\author{
Ning $\mathrm{Xu}^{1}$ \\ Art Academy of Northeast Agriculture University
}

\begin{abstract}
As an integral part of higher education, music education plays a fundamental role in promoting and enhancing comprehensive competency of undergraduate students. This paper conducts multi-dimensional deconstruction of the comprehensive competency of students, based on quantitative analysis, proposes the relations between music education and moral quality, humanistic quality, mental health, intelligence development and innovation ability. Through quantitative analysis on relations between music education and multiple competencies, this paper further validates that music education plays an irreplaceable role in enhancing students' overall competency. Our research mitigates deficiency in lack of quantitative analysis on music education among existing researches, and provides valuable insights into how universities and colleges should improve input, curriculum setting and evaluation on music education.
\end{abstract}

\section{Keywords}

Music Education • University Students • Overall Competency

\footnotetext{
${ }^{1}$ Correspondence to: Ning Xu (MA), Art Academy of Northeast Agriculture University, Harbin 150001, China. Email: xuning19810226@163.com

Citation: Xu, N., Analysis on Improvement of comprehensive competency in undergraduates by music education. Educational Sciences: Theory \& Practice, 18(5), 2062-2068. http://dx.doi.org/10.12738/estp.2018.5.105
} 
As the society develops, it is an increasing social need to enhance comprehensive competency in university students. Music education, as an effective approach to address this issue, is getting more and more attention (Harikumar \& Kumar, 2007). Though the importance of music education has been widely acknowledged, the world needs in-depth quantitative analysis on relations between music education and multiple student competencies (Dan, 2007; Bigenho, 2012).

Since the 1980s, the role of music education, as part of aesthetical education, in enhancing undergraduates' overall competency has been a topic to the interest of researchers (Mcclary, 1986). Some researchers, to address the existing problems and issues in routine music teaching, have focused on detailed aspects in music teaching, such as music theories and different performing styles and techniques (Garratt, 2006). Some researchers, from a perspective of cultivating aesthetic capacity, have conducted research on how music education helps with improvement of aesthetical capacity in students, such as formation of good aesthetic tastes and aesthetic judgements of higher accuracy (Chantler, 2002). In order to obtain an angel of best educational results, some have turned to how music education should be offered to different groups of audience, such as general education for non-music majors, curriculum setting for music majors (Spelman \& Killeavy, 1988). Setting from an angle of inheritance of music in different nations, some researchers have studied the impact of national music of varied types and styles on students' overall competency (Brand, 2004). Some have utilized the techniques of investigation and demonstration, categorized comprehensive competency for students, and studied relevance between music education and varied forms of competency through questionnaire surveying (Zhang, 2014).

Substantial research has been conducted by researchers on relation between music education and overall competency of students, with good research results so far. However, the existing research tends to be focused on theoretical analysis. Empirical analysis featuring quantitative methods has been rarely used in these researches. As a much-valued research method in social sciences, empirical analysis makes a good addition to theoretic analysis (Fredrickson, 2007). This paper adopts the method of empirical analysis, and conducts quantitative analysis on the relevance between music education and university students' moral quality, humanistic quality, mental health, intelligence development and innovation ability to understand how music education helps with development of overall competency of university students.

The first part of this paper is introduction. The second part discusses the meaning of overall competency of university students. The third part gives relevance analysis on music education and varied forms of competency, and the last part concludes the paper.

\section{Meaning of overall competency}

Table 1

College Students' Comprehensive Quality

\begin{tabular}{|c|c|c|c|c|c|}
\hline Dimension of quality & 1 & 2 & 3 & 4 & 5 \\
\hline Quality category & $\begin{array}{c}\text { Moral } \\
\text { character }\end{array}$ & $\begin{array}{c}\text { Humanistic } \\
\text { quality }\end{array}$ & $\begin{array}{l}\text { Mental } \\
\text { health }\end{array}$ & $\begin{array}{c}\text { Intellectual } \\
\text { development }\end{array}$ & $\begin{array}{c}\text { Innovation } \\
\text { ability }\end{array}$ \\
\hline
\end{tabular}

This paper deconstructs student's overall competency in five dimensions, including moral quality, humanistic quality, mental health, intelligence development and innovation ability, as in Table 1. This part studies the meaning of overall competency from these five dimensions. 


\section{Moral quality}

Moral quality means that, as restrained by social standards and code of conduct, individuals display cognition and behavioral habits with stabilized features during a certain period of time. In terms of moral quality, university students share commonality with general population, but they also have distinctive features specific to the group. Moral quality of the general population is mainly witnessed in maintaining social relations, social consensus, and principles. Faced with mostly semi-socialized relations, university students are at a key growing stage in terms of moral quality, and are highly flexible in this regard. Students have basic knowledge and social recognition, strong self-awareness, willingness to try out new things, and ability to be accountable partially for their own behaviors. So, with effective guidance and interaction, the extraneous factors can help with the formation and improvement of good moral quality in university students.

\section{Humanistic quality}

In the area of social sciences, humanistic quality means knowledge and capacity gained by natural persons or groups of persons through experiential learning or practical cognition. Humanistic quality normally consists of human knowledge reserve, humanistic spirit temperament and human behavior. Human knowledge reserve, contrary to natural knowledge reserve, means reserving knowledge of social sciences, such as literature, history, and philosophy. Humanistic spirit temperament refers to humanistic concern, consistent with the age the person is living in and the concept of people-orientation, that discusses the person-to-person relations, person-to-nature relations, and ultimate meaning of human being. Human behavior is a component of human quality and also one of its goals, an external representation of human knowledge reserve and humanistic spirit temperament. Higher education provides abundant resources, including good examples and cross-disciplinary knowledge, giving it inherent advantage in cultivating humanistic quality in university students.

\section{Mental health}

Mental health means that individuals can maintain normal state of mind during a certain period of time, and reflects the person's capacity in taking timely adjustments to changes in environment, and exerting active control on his or her sentiments. Subject to restraints of social roles and impacts of knowledge from varied sectors and systems, university students tend to develop and accumulate distorted cognition of knowledge as well as negative sentiments in their subconscious. This group faces higher risk of having psychological blocks such as anxiety, depression, over-sensitivity, and strong sense of inferiority. University students should be given prioritized attention on their state of mental health, and proper guidance, health checks, and active interference should also be provided. Research has shown that, among all these mitigation efforts, proper guidance is the most effective tool with the least costs. In daily practices, music, painting, and sports education have proven to be effective methods in maintaining good mental health and psychological healing. 


\section{Intelligence development}

Intelligence development means capacity to develop right thinking and speedy formation of thinking. Research on intelligence development falls into two categories: intelligence development based on brain structure, and intelligence development based on participating in social activities. Among them, the socialactivity-based approach on intelligence development research highlights active learning at the initiative of the individual and rights of allocation of time by the individual. In the process of participating in social activity, the level of anxiety can be significantly reduced, demonstrating positive feedbacks between activity participation and participating motivation by the individuals. And the effect of intelligence development is readily observable. So this form of intelligence development is widely acknowledged among researchers. Educational effect by music and other forms of art is part of intelligence development realized through social activity. Music education plays an irreplaceable role in good intellectual infrastructures and intelligence development.

\section{Innovation ability}

Innovation ability means the ability to break stereotype thinking under the pre-condition of having acquired sufficient knowledge. Cultivation of innovation ability is an important goal of higher education, and a heavily weighted factor in assessing results of university education. To cultivate innovation ability in university students is mostly realized through development of divergent thinking and critical thinking. Divergent thinking means a way of thinking free from restraints of rules, without pre-set condition, or clear logics, or fixated answers, dependent on instincts and imagination. Critical thinking, on the other hand, means a way of thinking that is free from any interference of current conclusions and leads to new independent conclusions. From these, cultivation of both divergent thinking and critical thinking is relevant to imagination, curiosity, desire for discovery, and initiatives. Music and other forms of art education happen to be very effective measures in order to cultivate non-intelligence factors.

\section{Relevance analysis between music education and overall competency of students}

This paper adopts questionnaires to survey targeted university students, and conducts quantitative analysis on the relevance between music education and overall competence of students based on survey results. Questionnaire questions are designed to provide solid theoretic support for analysis from five dimensions, including moral quality, humanistic quality, mental health, intelligence development and innovation ability, as discussed in part 2. Survey objects include university students from the first year to the fourth year without restraints on majors. 250 questionnaires were delivered to each grade, meaning a total of 1000 questionnaires. 967 effective questionnaires were recollected. Matlab was used for relevance analysis.

\section{Relevance analysis between music education and moral quality}

Based on answers to designed music-related questions in questionnaires, the surveyed students were grouped into three groups: high music quality, medium music quality, and low music quality. Then, we compared the 
correct answer rates of each group on the moral quality related questions. Table 2 includes the comparative results.

Table 2

The Correct Answer Rate of Moral Character After Grouping by Music Quality

\begin{tabular}{clccc}
\hline \multirow{2}{*}{ Number } & \multicolumn{1}{c}{ Questionnaire } & $\begin{array}{c}\text { Group with } \\
\text { high music } \\
\text { quality (\%) }\end{array}$ & $\begin{array}{c}\text { Group with } \\
\text { middle music } \\
\text { quality (\%) }\end{array}$ & $\begin{array}{c}\text { Group with } \\
\text { low music } \\
\text { quality (\%) }\end{array}$ \\
\hline 1 & Do you often engage in voluntary activities? & 76.9 & 58.2 & 49.1 \\
2 & Are we concerned about vulnerable groups? & 53.4 & 49.7 & 51.2 \\
3 & Are you willing to abide by social ethics? & 78.6 & 79.2 & 72.8 \\
4 & Do you often reflect on yourself? & 89.7 & 62.0 & 65.3 \\
5 & Do you agree with the importance of law? & 91.5 & 89.9 & 92.4 \\
\hline
\end{tabular}

From data in Table 2, on questions "if you often take part in volunteer activities?" and "if you often have self-reflections?", the group of high music quality has significantly higher correct rate than the other two groups, while on other questions, the correct rates remained consistent among the three groups. It means that higher music quality plays a positive role in enhancing certain aspects of moral quality in university students.

\section{Relevance analysis between music education and humanistic quality}

Table 3

\begin{tabular}{clccc}
\multicolumn{2}{c}{ The Correct Answer Rate of Humanistic Quality After Grouping by Music Quality } \\
\hline \multirow{2}{*}{ Number } & \multicolumn{1}{c}{ Questionnaire } & $\begin{array}{c}\text { Group with } \\
\text { high music } \\
\text { quality (\%) }\end{array}$ & $\begin{array}{c}\text { Group with } \\
\text { Middle music } \\
\text { quality (\%) }\end{array}$ & $\begin{array}{c}\text { Group with } \\
\text { low music } \\
\text { quality (\%) }\end{array}$ \\
\hline 1 & Do you have basic knowledge of humanities? & 60.2 & 48.2 & 45.6 \\
2 & Are you interested in art? & 78.1 & 58.1 & 23.5 \\
3 & Do you have basic appreciation of aesthetics? & 80.6 & 69.4 & 25.8 \\
4 & Do you have a constant reflection on human & 58.7 & 60.1 & 67.2 \\
5 & values? & 42.6 & 35.9 & 31.5 \\
\hline
\end{tabular}

We compare the correct answer rates of each group on the humanistic quality related questions and include comparative results in Table 3.

From data in Table 3, we see that high music quality has significantly higher correct rate to questions "if you have fundamental human knowledge?", "if you have strong interest in art?" and "if you have fundamental art apprehension ability?" While on other questions, correct rates remained consistent or minor gaps among the three groups. It shows that music education helps promote interest in human knowledge and comprehensive development of students.

\section{Relevance analysis between music education and mental health}

We compare the correct answer rates of each group on the mental health questions and include comparative results in Table 4.

From data in Table 4, good music quality helps university students establish positive mentality, maintain good inter-personal relations, and face success and difficulty in life with a right mind-set. 
Table 4

The Correct Answer Rate of Mental Health After Grouping by Music Quality

\begin{tabular}{clccc}
\hline \multirow{2}{*}{ Number } & \multicolumn{1}{c}{ Questionnaire } & $\begin{array}{c}\text { Group with } \\
\text { high music } \\
\text { quality (\%) }\end{array}$ & $\begin{array}{c}\text { Group with } \\
\text { middle music } \\
\text { quality (\%) }\end{array}$ & $\begin{array}{c}\text { Group with } \\
\text { low music } \\
\text { quality (\%) }\end{array}$ \\
\hline 1 & Are you compatible with people? & 78.2 & 54.8 & 60.2 \\
2 & Do you often have pessimism? & 89.4 & 71.8 & 73.6 \\
3 & Are you able to cope with failure? & 75.1 & 63.8 & 50.1 \\
4 & Do you often worry? & 20.7 & 22.5 & 21.4 \\
5 & Do you often suffer from insomnia? & 34.2 & 31.8 & 36.0 \\
\hline
\end{tabular}

\section{Relevance analysis between music education and intelligence development}

We compare the correct answer rates of each group on the intelligence development questions and include comparative results in Table 5 .

Table 5

The Correct Answer Rate of Intellectual Development After Grouping by Music Ouality

\begin{tabular}{clccc}
\hline \multirow{2}{*}{ Number } & \multicolumn{1}{c}{ Questionnaire } & $\begin{array}{c}\text { Group with } \\
\text { high music } \\
\text { quality (\%) }\end{array}$ & $\begin{array}{c}\text { Group with } \\
\text { middle music } \\
\text { quality (\%) }\end{array}$ & $\begin{array}{c}\text { Group with } \\
\text { low music } \\
\text { quality (\%) }\end{array}$ \\
\hline 1 & Do you understand the level of IT? & 47.6 & 21.8 & 14.4 \\
2 & Do you understand the world literature? & 42.0 & 15.6 & 17.2 \\
3 & Do you know geography knowledge? & 38.7 & 19.4 & 19.5 \\
4 & Do you know China's contribution? & 37.2 & 40.6 & 38.1 \\
5 & Do you know prehistory civilization? & 9.2 & 8.5 & 7.6 \\
\hline
\end{tabular}

From data in Table 5, music education contributes significantly to students' intelligence development. Students with higher level of music quality are more willing to learn more knowledge in varied areas.

\section{Relevance analysis between music education and innovation ability}

We compare the correct answer rates of each group on the innovation ability questions and include comparative results in Table 6.

From data in Table 6, music education is helpful in stimulating curiosity and desire for knowledge in university students. It helps them find extensive hobbies and enhance their capacity in research and teamwork.

Table 6

The Correct Answer Rate of Innovation Ability After Grouping by Music Quality

\begin{tabular}{ccccc}
\hline \multirow{2}{*}{ Number } & Questionnaire & $\begin{array}{c}\text { Group with } \\
\text { high music } \\
\text { quality (\%) }\end{array}$ & $\begin{array}{c}\text { Group with } \\
\text { middle music } \\
\text { quality (\%) }\end{array}$ & $\begin{array}{c}\text { Group with } \\
\text { low music } \\
\text { quality (\%) }\end{array}$ \\
\hline 1 & Do you have an interest in new things? & 68.5 & 47.2 & 48.5 \\
2 & Do you have a thirst for knowledge? & 70.4 & 52.3 & 54.9 \\
3 & Do you have the basic research ability? & 85.6 & 65.9 & 65.2 \\
4 & Do you have a wide range of hobbies? & 90.3 & 80.6 & 72.9 \\
5 & Do you have good teamwork skills? & 58.1 & 42.8 & 39.4 \\
\hline
\end{tabular}




\section{Conclusion}

This paper studies the meaning of overall competency in university students from multiple dimensions, including moral quality, humanistic quality, mental health, intelligence development and innovation ability, conducts statistical analysis on questionnaire results, and identifies relevance between music education and overall competency of university students. The results of this paper demonstrate that music education is very important to the enhancement of overall competence in university students, and provides universities with guidance on resource input, curriculum setting, and assessment on music education.

\section{References}

Bigenho, M. (2012). Intimate distance: Andean music in japan. Journal of Japanese Studies, 39(2), 418-422. http://dx.doi.org/10.1215/9780822395317

Brand, M. (2004). Collectivistic versus individualistic cultures: a comparison of American, Australian and Chinese music education students' self-esteem. Music Education Research, 6(1), 57-66. http://dx.doi.org/10.1080/1461380032000182830

Chantler, A. (2002). Revisiting e. t. a. Hoffmann's musical hermeneutics. International Review of the Aesthetics \& Sociology of Music, 33(1), 3-30. http://dx.doi.org/10.2307/4149784

Dan, R. (2007). Frequently overlooked and rarely listened to: music therapy in gastrointestinal endoscopic procedures. World Journal of Gastroenterology, 13(33), 4533-4533. http://dx.doi.org/10.3748/wjg.v13.i33.4533

Fredrickson, W. E. (2007). Perceptions of college-level music performance majors teaching applied music lessons to young students. International Journal of Music Education, 25(1), 72-80. http://dx.doi.org/10.1177/0255761407074893

Garratt, J. (2006). Review: Programming the absolute: nineteenth-century german music and the hermeneutics of the moment. German Studies Review, 27(2), 383. http://dx.doi.org/10.1093/m1/85.3.454

Harikumar, R., \& Kumar, S. (2007). Colonoscopy and the role of music therapy: how to go about an ideal protocol?. World Journal of Gastroenterology, 13(23), 3272. http://dx.doi.org/10.3748/wjg.v13.i23.3272

Mcclary, S. (1986). A musical dialectic from the enlightenment: Mozart's "piano concerto in g major, k. 453", movement 2. Cultural Critique(4), 129-169. http://dx.doi.org/10.2307/1354338

Spelman,B., \& Killeavy, M. (1988). Music standards and dispositions of students entering a college of education. Irish Educational Studies, 7(1), 102-123. http://dx.doi.org/10.1080/0332331880070111

Zhang, F. (2014). Impact of music education on comprehensive qualities of college students - Based on some universities sample survey from Liaoning Province. Modern Education Management, 6, 125-128. http://10.16697/j.cnki.xdjygl.2014.06.001 